\title{
LOSS OF NITROGEN FROM THE FOREST FLOOR BY BURNING ${ }^{1}$
}

\author{
By H. KNIGHT ${ }^{2}$
}

\section{ABSTRACT}

Burning experiments conducted in the laboratory indicated a 25-64 per cent loss of nitrogen from the forest floor at temperatures of $300-700^{\circ} \mathrm{C}$. Burning increased the nitrogen concentration of the residual material, but the total amount of nitrogen decreased. This may explain the frequent reports of an increase in nitrogen after burning.

\section{INTRODUCTION}

It is generally acknowledged that burning of the forest floor results in a loss of nitrogen through volatilization (Lutz and Chandler, 1947, Ovington, 1962). However, there are frequent reports (Ahlgren and Ahlgren, 1960) that burning increased soil nitrogen. Some of these reports attibuted the increases to biological fixation of nitrogen. However, it has been estimated that only 35-70 pounds of nitrogen per acre per year may be fixed by organisms in forest soils (Lutz and Chandler, 1947). Even if this figure were doubled it would be small compared with the reported increases.

In the coastal Douglas fir region of British Columbia slash-burning is a common forest management practice. Yet information is lacking on the amount of nitrogen lost through burning. As nitrogen is an essential element for plant growth and its reserve in the soil is a key to forest productivity, it is imperative to know the effects of slash-burning on soil nitrogen.

The object of this study was to determine the effect of slash-burning on the nitrogen content of the forest floor. This surface organic layer of the soil has a high reserve of nitrogen, and of all the soil horizons it is changed the most after slash-burning.

\section{METHOD}

An indication of nitrogen volatilization from burning the forest floor can perhaps best be demonstrated under controlled laboratory conditions, which would approximate conditions in the field.

\footnotetext{
${ }^{1}$ A portion of a thesis submitted in partial fulfillment of the requirements for the Ph.D. degree, University of Washington, Seattle, Washington, 1964.

${ }^{2}$ Research Officer, Canada Department of Forestry, Forest Research Laboratory, Calgary, Alberta.
} 
Samples of forest floor ( $\mathrm{L}+\mathrm{F}+\mathrm{H}$ organic layers) from an old growth western hemlock - Douglas fir forest were the test material used. Six random, $4 \mathrm{gm}$ samples of air dried forest floor material of approximately the same volume were weighed out for each of seven burning treatments and placed in the oven at $70 \mathrm{C}$ for 24 hours. The samples were removed from the oven six at a time, and each group of six placed in a muffle furnace at different temperatures for 20 minutes. The temperatures were $70,75,100,200,500$ and $700 \mathrm{C}$. The highest of these were much lower than the following temperatures reached by slash fires in the field: $1750 \mathrm{~F}$ (Beaufait, 1960), $2300 \mathrm{~F}$ (Countryman, 1964), and $1600 \mathrm{~F}$ (Davis and Martin, 1960). After 20 minutes in the furnace the samples were placed in a desiccator and the loss of weight determined. The samples were then ground with a mortar and pestle and the nitrogen content of each determined by the Kjeldahl method (Jackson, 1958).

\section{Results AND Discussion}

The total nitrogen and loss of weight of forest floor samples after heating in muffle furnace at temperatures of 70-700 $\mathrm{C}$ are presented in Table 1. Each weight loss and nitrogen figure represents a mean of six samples.

The dry weight of the old growth hemlock - fir forest floor based on 12 one-foot square samples was estimated to be $46,470 \mathrm{lbs}$ per acre (Knight, 1964). Table 1 shows the nitrogen content of the forest floor was 1.26 per cent (100 C treatment) or a total of $586 \mathrm{lbs}$ of nitrogen per acre. Therefore it is estimated that $149 \mathrm{lbs}$ of nitrogen per acre would be lost at $300 \mathrm{C}$ and $367 \mathrm{lbs}$ per acre at $700 \mathrm{C}$. This represents a $25-64$ per cent loss of nitrogen from the forest floor by volatilization. These values are reasonably close to the estimate of nitrogen loss from light to moderate burning in the field (Knight, 1964).

Nitrogen values given in Figure 1 use two different bases for calculation. Curve $\mathrm{A}$ is based on the weights after the samples were muffled. No standard weight basis is used for the calculation and no allowance is made for the differences in the loss of weight among samples. It can be seen that at temperatures from $100-500 \mathrm{C}$ the nitrogen increases, while at $700 \mathrm{C}$ a large loss occurs. Curve $\mathrm{B}$ is based on a standard oven-dry weight and takes into

TABLE 1

Total Nitrogen and Mean loss of Weight of the Forest Floor after Heating in a Muffle furnace at Various Temperatures

\begin{tabular}{ccccc}
\hline \multirow{2}{*}{$\begin{array}{c}\text { Tempersture } \\
\text { Celcius }\end{array}$} & $\begin{array}{c}\text { Weight Loss } \\
\text { (Per cent) }\end{array}$ & $\begin{array}{c}\text { No standard } \\
\text { reight basis } \\
\text { (Per cent) }\end{array}$ & $\begin{array}{c}\text { Nitrogen } \\
\text { Oven-dry } \\
\text { weight basis } \\
\text { (Per cent) }\end{array}$ & $\begin{array}{c}\text { Loss bs treatment } \\
\text { (lbs per acre) }\end{array}$ \\
\hline 70 & Nil & $1.28 \pm 0.09$ & 1.28 & \\
75 & Nil & $1.21 \pm 0.04$ & 1.21 & \\
100 & Nil & $1.26 \pm 0.10$ & 1.26 & \\
200 & 14.05 & $1.47 \pm 0.18$ & 1.26 & 149 \\
300 & 38.52 & $1.57 \pm 0.18$ & 0.94 & \\
500 & 60.56 & $1.70 \pm 0.16$ & 0.67 & 367 \\
700 & 62.98 & $1.23 \pm 0.08$ & 0.46 & \\
\hline
\end{tabular}




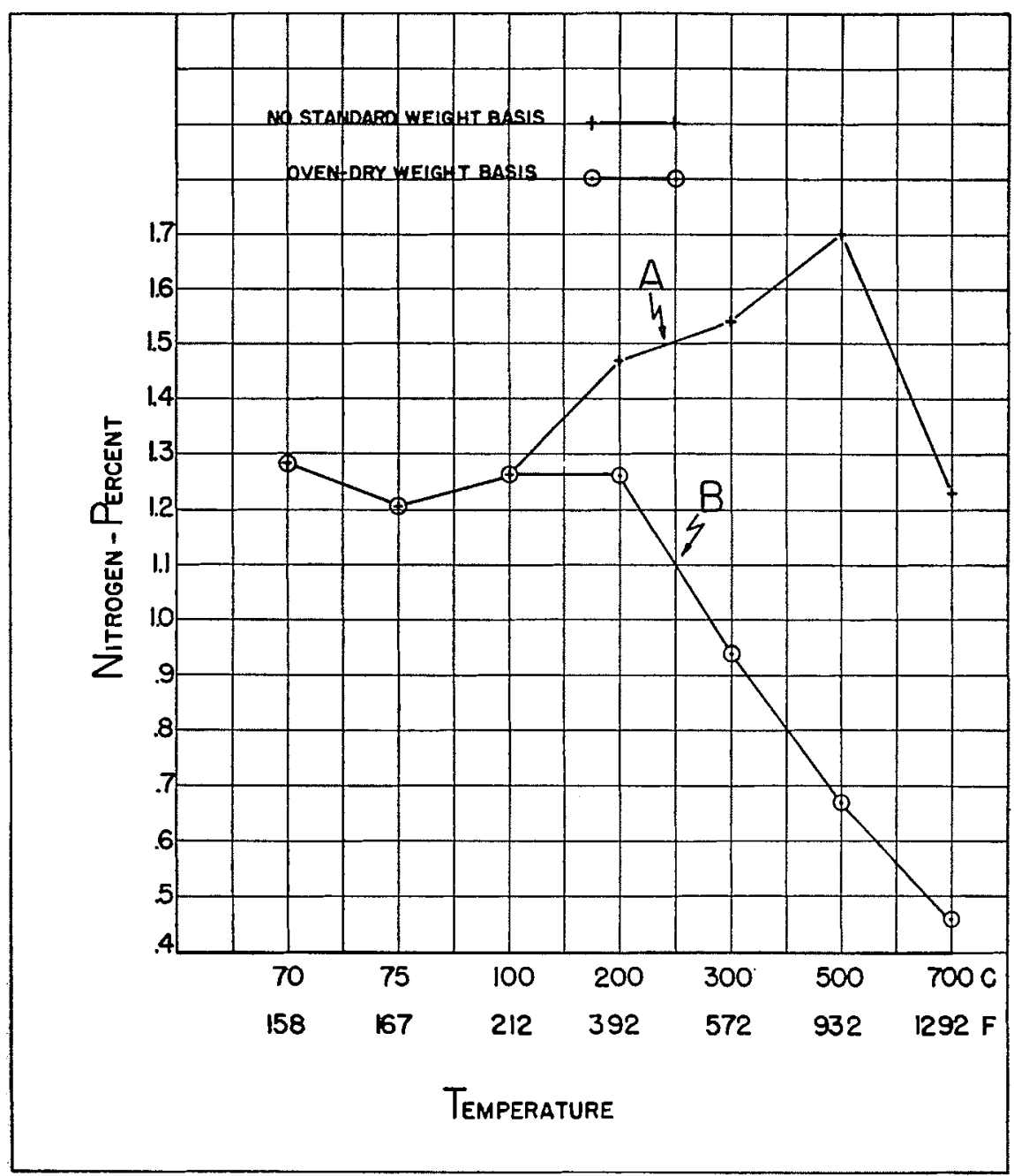

FIGURE 1. Total Nitrogen in the Forest Floor After Heating to Various Temperatures 
account the change in weight of the forest floor material after muffling. This curve shows there is little loss of nitrogen until $200 \mathrm{C}$ is exceeded. At 300-700 C large losses of nitrogen are indicated.

The results indicate that burning can increase the nitrogen concentration of the residual material. However, the total amount of nitrogen decreases. This suggests that increases in nitrogen after burning that have been reported in the literature, are increases in the nitrogen concentration of the residual material as one might expect, and not increases in total amount.

It would appear that slash-burning may appreciably reduce the nitrogen content of the forest floor. Thus it is imperative to consider how this will affect future forest productivity.

\section{REFERENCES}

AHLGREN, L. F. and C. E. AHLGREN, 1960. Ecological effects of forest fires. Bot. Rev. $26(4): 483-543$.

BEAUFAIT, W. R. 1960. Influences of shade level and site treatment, including fire, on germination and early survival of Pinus Banksiana. Forestry Division, Mich. Dept. Conservation, Lansing, Mich., Tech. Pub. 1.

COUNTRYMAN, C. M. 1964. Mass fires and fire behavior. U.S. Forest Service, Pacific Southwest Region. Res. Pa. PSW-19.

DAVIS, L. S. and R. E. MARTIN. 1960. Time-temperature relationships of test head fires and backfires, U.S. Forest Service, Southeastern Forest Exp. Sta. Res. Note 148.

JACKSON, M. L. 1958. Soil chemical analysis. Prentice-Hall Inc. Englewood Cliffs, N.J.

KNIGHT, H. A. W. 1964. Some effects of slash-burning and clearcut logging on soil properties and initial tree growth. Ph.D. Thesis, University of Washington, Seattle, Wash. $191 \mathrm{pp}$

LUTZ, H. J. and R. F. CHANDLER. 1946. Forest soils. John Wiley and Sons, Inc. New York.

OVINGTON, J. D. 1962. Quantitative ecology and the woodland ecosystem concept. Advances in Ecological Research, Vol. 1. 103-192. Academic Press. 